\title{
ZINC ADSORPTION BY STERILIZED AND NON-STERILIZED SOIL IN THE PRESENCE OF CITRATE AND CATECHOL
}

\author{
P. Chairidchai and G. S. P. Ritchie
}

ABSTRACT: The effect of organic ligands on zinc ( $\mathrm{Zn})$ adsorption in the Thizosphere may be influenced by microbial activity depleting the concentration of the ligand over time. Zinc adsorption by sterile and non-sterile lateritic soil was measured by shaking the soils with $\mathrm{Zn}$ solutions at a soil-liquid ratio of $1: 5$ for five periods of time ranging from $17-480 \mathrm{~h}$. The concentrations of $\mathrm{Zn}$ and the ligands were determined after the selected times. The speciation of $\mathrm{Zn}$ was then estimated.

Changes in $\mathrm{Zn}$ adsorption with time in the presence of organic ligands were due to changes in $\mathrm{pH}$ and $\mathrm{Zn}$ complexation associated with the addition and breakdown of the organic ligands and with the technique of sterilization. Zinc adsorption was higher in non-sterile than in sterile soil. Adsorption in the presence of citrate was lower than in its absence except in non-sterile soil after $72 \mathrm{~h}$. The adsorption in the presence of catechol was similar to that in its absence.

\section{INTRODUCTION}

The adsorption of $\mathrm{Zn}$ has been demonstrated to be influenced by the presence of organic ligands $(1,2)$. However, the effect of organic ligands on the adsorption of $\mathrm{Zn}$ by soil in rhizosphere may be altered due to microbial activity. In the rhizosphere, the population of micro-organisms can be 10 times greater than in the bulk soil $(3,4)$, and therefore, their activity in this zone is believed to be high $(5)$. Soil micro-organisms can often use organic ligands as their substrates (6) which may cause a depletion of the ligand concentration in the rhizosphere. However, the rhizosphere is a dynamic system where the production of organic root exudates is 
occurring frequently. The concentration of organic ligands at any one time can be quite variable due to the rate of their replacement which depends on factors such as plant age, soil temperature, and moisture and nutrient availability $(7,8)$.

Our objective was to study the effect of organic ligands on $\mathrm{Zn}$ adsorption by non-sterile and sterile soils after various periods of time. Citrate and catechol were chosen because $\mathrm{Zn}$ adsorption has been found to be smaller in the presence of citrate than in its absence whereas catechol did not have any effect on adsorption (2). Unlike the rhizosphere, the system used in this experiment was much simpler in that there was no replacement of ligands taking place. Therefore, the effect of organic ligands varied with time.

\section{MATERIALS AND METHODS}

The influence of soil micro-organisms on the effect of organic ligands on zinc adsorption by a lateritic soil was studied by measuring adsorption in sterilized and non-sterilized soil (Northcote classification: Dy 5.51, Soil Taxonomy: Entisol) after 17 to $480 \mathrm{~h}$. The soil was collected from Bakers Hill, Western Australia and contained $0.004 \mu \mathrm{mol} / \mathrm{g}$ of DTPA-extractable $\mathrm{Zn}, 2.1 \%$ organic $\mathrm{C}$, and had a cation exchange capacity of $6.9 \mathrm{cmolc} / \mathrm{kg}$.

A solution of $0.003 \mathrm{M} \mathrm{KCl}$ containing $2.5 \mu \mathrm{mol} / \mathrm{g} \mathrm{Zn}\left(\mathrm{NO}_{3}\right) 2$, and 0 or $1 \mathrm{mM}$ of citric acid or catechol was sterilized by filtration $(<0.22 \mu \mathrm{m})$. Twenty milliliters of the solutions were then shaken with duplicate, $4 \mathrm{~g}$ subsamples of sterile or non-sterile soil for $17,72,144,240$, and $480 \mathrm{~h}$. The sterile soil was prepared by autoclaving $\left(121^{\circ} \mathrm{C}\right.$, and $400 \mathrm{KPa}$, for $20 \mathrm{~min}$ twice, $24 \mathrm{~h}$ apart). After the selected times, the soil mixture was centrifuged ( $1000 \mathrm{~g}$ force), and then filtered $(<0.45 \mu \mathrm{m})$. The $\mathrm{pH}$ of the filtrates were measured. Microbial counting (9) confirmed that sterilization was effective. The filtrates were analyzed for $\mathrm{Zn}$ (atomic absorption spectrometry), catechol (10), and citrate (11).

Zinc speciation was estimated by a chemical equilibrium program TITRATOR (12). Ionic strengths of solutions were calculated by the program to compensate for the contribution of components other than $\mathrm{KCl}$. In all cases, calculated values of ionic strength were lower than 0.004 . The species considered were the free $\mathrm{Zn}$ ion $\left(\mathrm{Zn}^{2+}\right)$, the hydrolysed $\mathrm{Zn}\left(\mathrm{ZnOH}^{+}\right)$, and $\mathrm{Zn}$ citrate ( $\mathrm{Zncit}$ ) or $\mathrm{Zn}$ catechol complex (Zncat). The values for the $\log \mathrm{K}$ used in the calculation were from Lindsay (13) and Martell and Smith (14). 
The data were analyzed by linear regression. Standard errors were estimated and are shown as error bars in the figures if the standard error was greater than the diameter of the data point.

\section{RESULTS}

Zinc Adsorption: Zinc adsorption in all treatments increased with time (Fig. 1). For sterile soils, the maximum adsorption was reached after $240 \mathrm{~h}$ (Fig. 1a) whereas the increase in the adsorption by non-sterile soil between 17 and $480 \mathrm{~h}$ was never greater than $6 \%$ (Fig. 1b).

The effect of the ligands on $\mathrm{Zn}$ adsorption depended on the ligand type. Catechol did not affect $\mathrm{Zn}$ adsorption either in sterile (Fig. 1a) or non-sterile soil (Fig. 1b) . On the other hand, the effect of citrate varied with the sterilization. In sterile soil, the presence of citrate decreased $\mathrm{Zn}$ adsorption at all times (Fig. 1a). In non-sterile soil, a marked decrease in $\mathrm{Zn}$ adsorption due to the presence of citrate occurred after $17 \mathrm{~h}$, but the decrease became smaller and eventually disappeared at later times (Fig. 1b).

Sterilization also affected $\mathrm{Zn}$ adsorption. At constant time, adsorption was greater in a non-sterile than a sterile soil (Fig. 1). The sterilization effect was greatest in the presence of citrate (Fig. 1). In the absence of a ligand or in the presence of catechol, the difference was less than $1 \%$.

In the presence of organic ligands, $\mathrm{Zn}$ adsorption decreased linearly $\left(\mathrm{r}^{2}\right.$ $>0.99$ ) with the increasing concentration of Zncit (Fig. 2a), exponentially with Zncat (Fig. 2b) and more than $99 \%$ of its variation could be explained by the combined effect of both complexed species and $\mathrm{ZnOH}^{+}$in a single equation. Adsorption also increased with $\mathrm{pH}$ (Fig. 3).

Zinc in Solution: Zinc concentration in soil solution decreased with time (Fig. 4). The initial decrease (from $17-48 \mathrm{~h}$ ) was greatest in the presence of citrate, the effect being greater in the non-sterile soil than in the sterile soil. $\mathrm{Zn}$ concentration in solution of the non-sterile soil at $480 \mathrm{~h}$ was only $18.9 \%$ of that at $17 \mathrm{~h}$ in the presence of citrate, whereas it was $44.6 \%$ in the sterile soil.

The concentration of each $\mathrm{Zn}$ species in solution varied with time and sterilization methods (Fig. 5) Both $\mathrm{Zncit}^{-}$and Zncat decreased with time in solutions from sterile and non-sterile soils (Fig. $5 \mathrm{a}$ and $\mathrm{b}$ ). However, the decrease of both species was greater in the non-sterile soil. Zinc $\left(\mathrm{Zn}^{2+}\right)$ in all treatments, except in the presence of citrate in the non-sterile soil, also decreased with time 


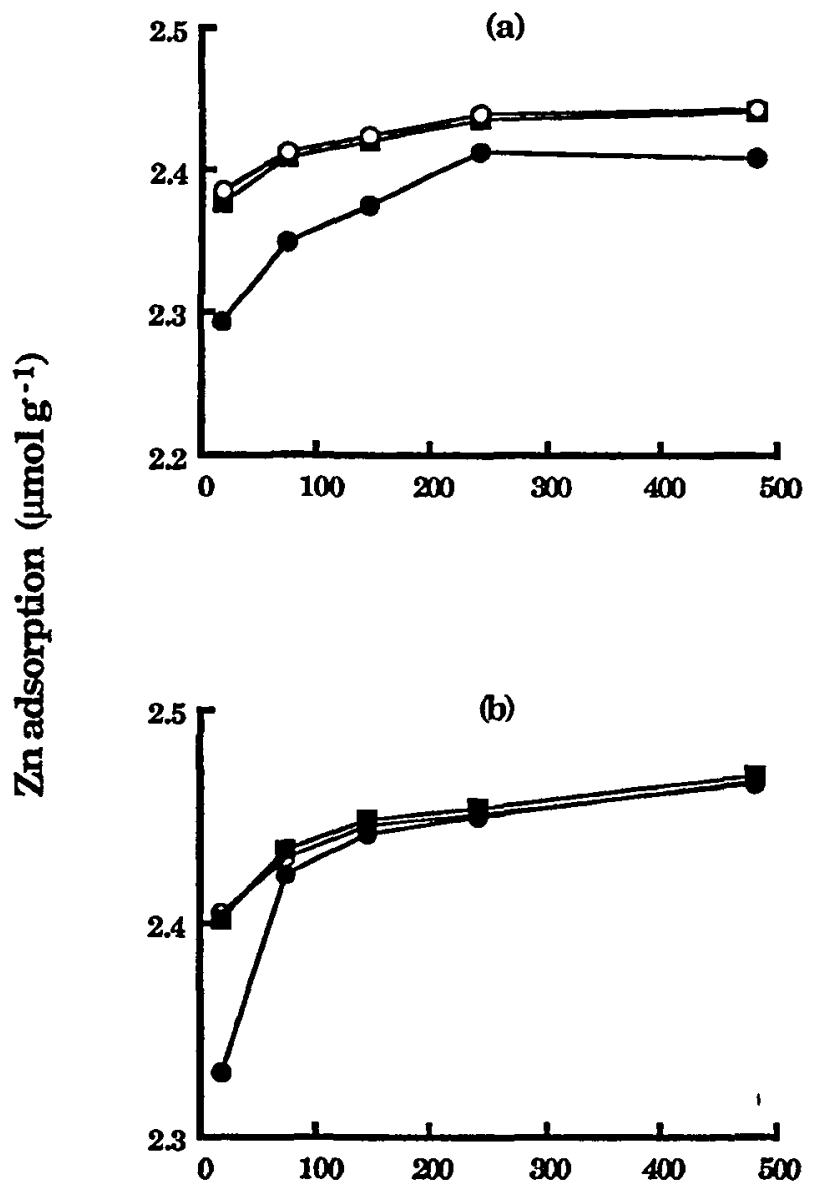

\section{Time (h)}

FIGURE 1. The relationship between reaction time and $\mathrm{zn}$ adsorption by a lateritic soil in the absence (O) or in the presence of citrate (O) or catechol (E) by (a) sterile and (b) non-sterile soils. 

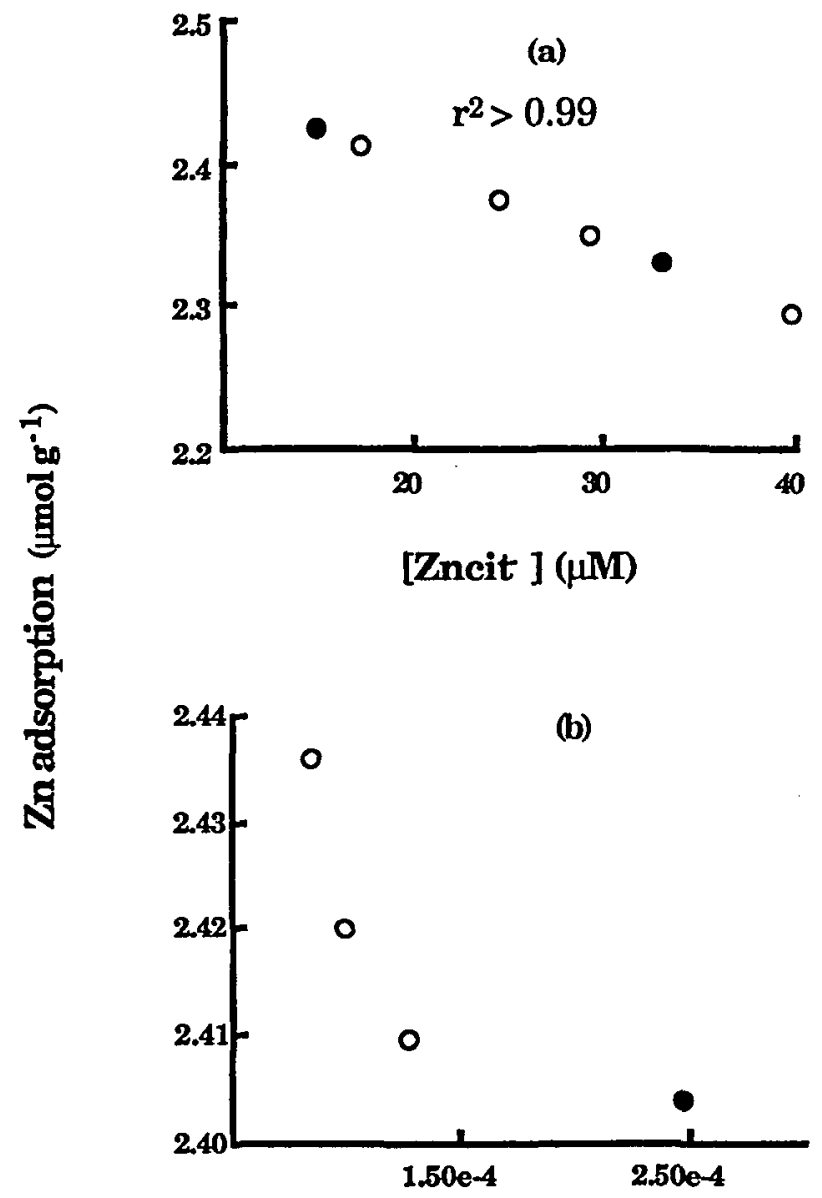

\section{[Zncat] $(\mu \mathbf{M})$}

FIGURE 2. The relationship between the

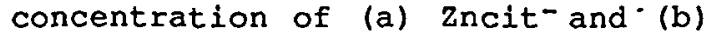
zncat on $\mathrm{Zn}$ adsorption by sterile (O) and non-sterile soils (O). 


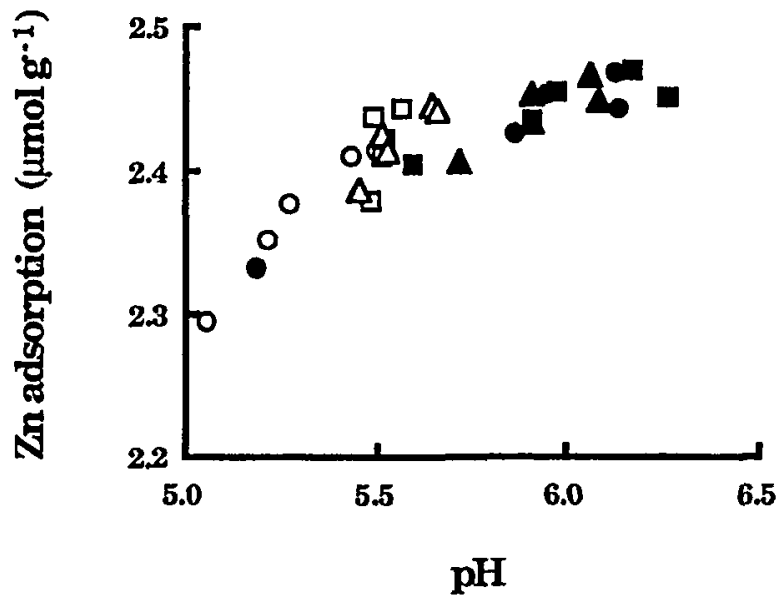

FIGURE 3. The relationship between $\mathrm{pH}$ and $\mathrm{zn}$ adsorption by sterile soil lopen symbols) and non-sterile soils (closed symbols) in the absence $(\Delta, \boldsymbol{\Delta})$ or the presence of citrate $(O, 0)$ and catechol $(0, \mathbf{E})$.

(Fig. $6 \mathrm{a}$ and b). In the latter case, there was an increase between 72 and $144 \mathrm{~h}$ (Fig. 6b). $\mathrm{ZnOH}^{+}$in the sterile soils generally decreased with time (Fig. $6 \mathrm{c}$ ). In non-sterile soils, $\mathrm{ZnOH}^{+}$increased from 17 to $144 \mathrm{~h}$, decreased up to $240 \mathrm{~h}$ and remained unchanged up to $480 \mathrm{~h}$ (Fig. 6d). The increase between 17 and $144 \mathrm{~h}$ was more marked in the presence of citrate than catechol which was more marked than in the absence of a ligand (Fig. 6d).

Ligand Concentrations: Sterilization also affected the ligand concentrations in the soil solutions. In the non-sterile treatments, the concentration of citrate decreased markedly from $631 \mu \mathrm{M}$ at $17 \mathrm{~h}$ to zero at $144 \mathrm{~h}$, whereas the concentration changed only slightly in the sterile soil (Fig. 7a). The concentration of catechol decreased from $789 \mu \mathrm{M}$ at $17 \mathrm{~h}$ to zero within $72 \mathrm{~h}$ when the soil was not sterilized. After sterilization, however, catechol concentrations remained higher than $534 \mu \mathrm{M}$ until $240 \mathrm{~h}$ (Fig. $7 \mathrm{~b}$ ).

The effect of $\mathrm{pH}$ on the concentrations of the organic ligands depends on the type of ligand. Citrate concentration decreased with increasing $\mathrm{pH}$ (Fig. 8a) whereas the concentration of catechol was independent of $\mathrm{pH}$ (Fig. 8b): 


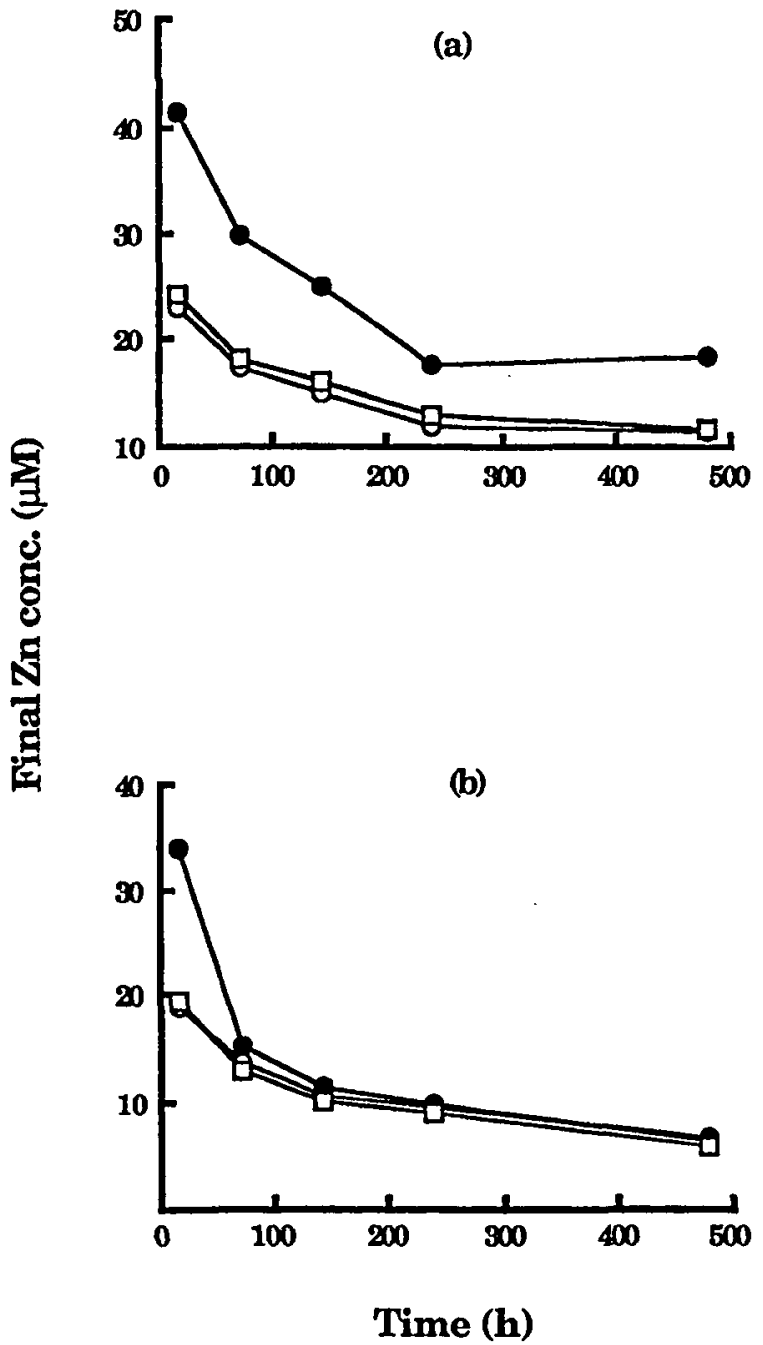

FIGURE 4. The relationship between reaction time and the concentration of $\mathrm{Zn}$ in solution of (a) sterile and (b) non-sterile soils in the absence(O) or presence of citrate (O) or catechol (W). 

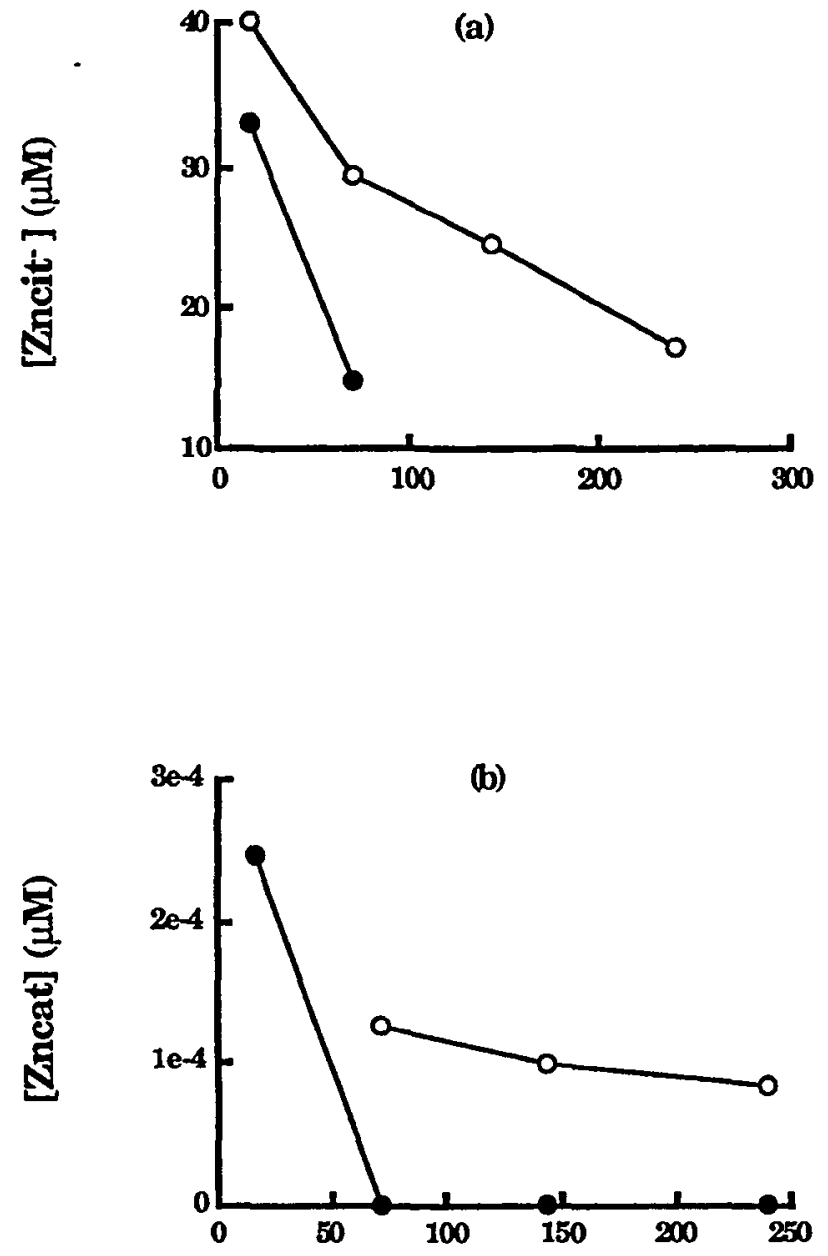

Time (h)

FIGURE 5. The relationship between reaction time and the concentration of (a) zncit-and (b) zncat in the sterile (O) and non-sterile soils(O). 

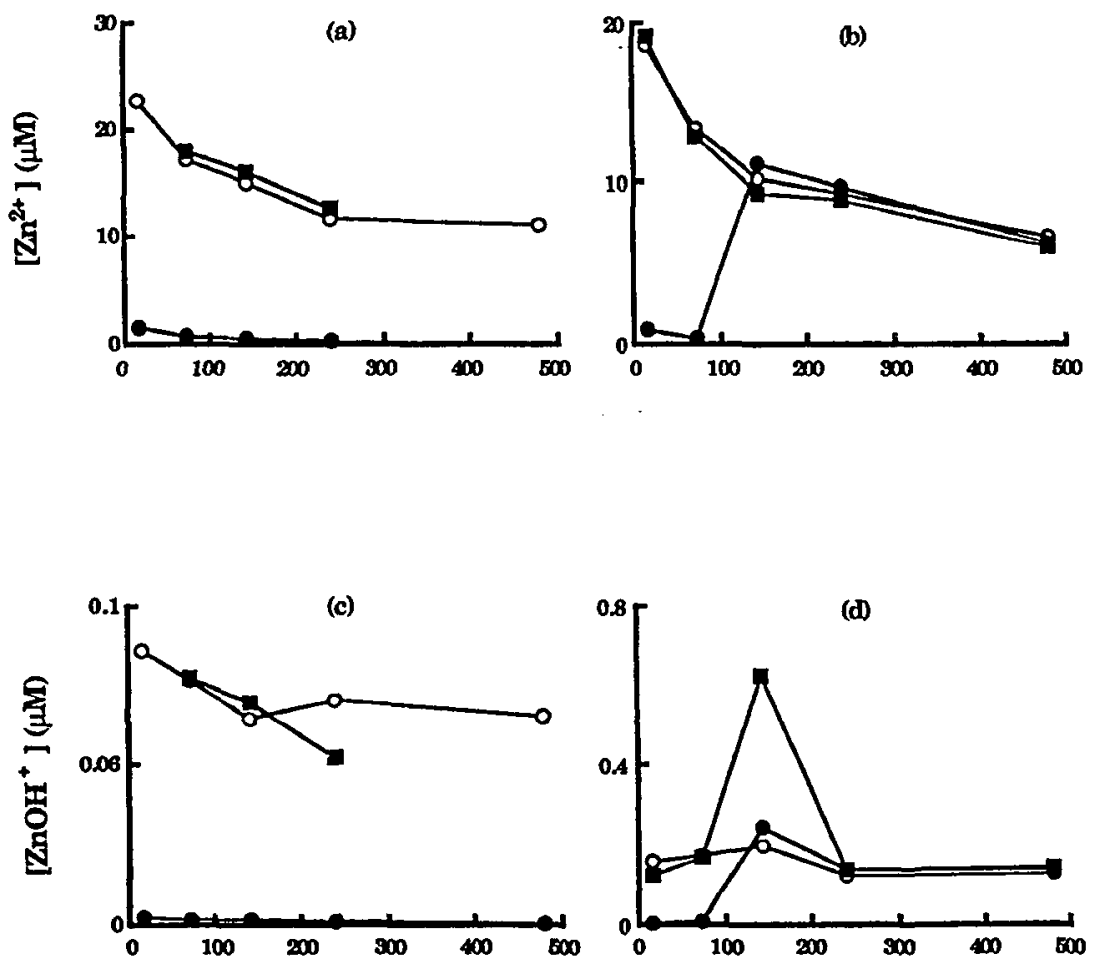

\title{
Time (h)
}

\begin{abstract}
FIGURE 6. The relationship between reaction time and the concentration of $\mathrm{Zn}^{2+}(\mathrm{a}, \mathrm{b})$ and $\mathrm{2nOH}^{+}(\mathrm{c}, \mathrm{d})$ in the absence (O) or presence of citrate $(O)$ or catechol $(E)$ in $(a, c)$ sterile and $(b, d)$ non-sterile solls.
\end{abstract}

pH: At a constant time, sterilization decreased soil $\mathrm{pH}$ in the absence of organic ligands. The $\mathrm{pH}$ of soil solution increased with time (Fig. 9). In the presence of citrate and catechol, the $\mathrm{pH}$ of non-sterile soil increased more rapidly than those in the other treatments in the first $144 \mathrm{~h}$, and the increase up to this time was as high as 0.9 of a pH unit in the presence of citrate and about 0.5 unit in the presence of catechol. However, the pHs of these soils dropped 0.2-0.3 units from 144 to $240 \mathrm{~h}$ before increasing again. The $\mathrm{pH}$ of the sterile soils increased only marginally within the studied length of time. 

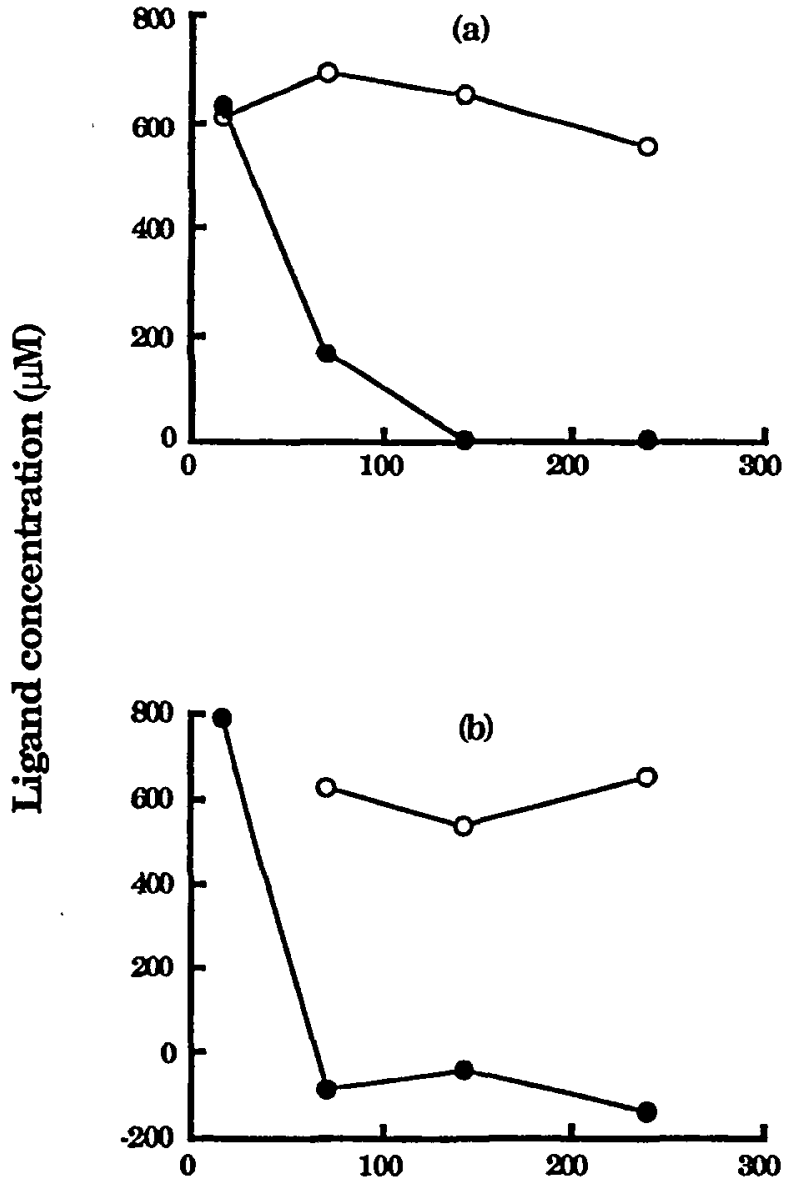

\section{Time (h)}

FIGURE 7. The relationship between reaction time and the concentration of (a) citrate and (b) catechol in sterile (O) and non-sterile soils(O). 

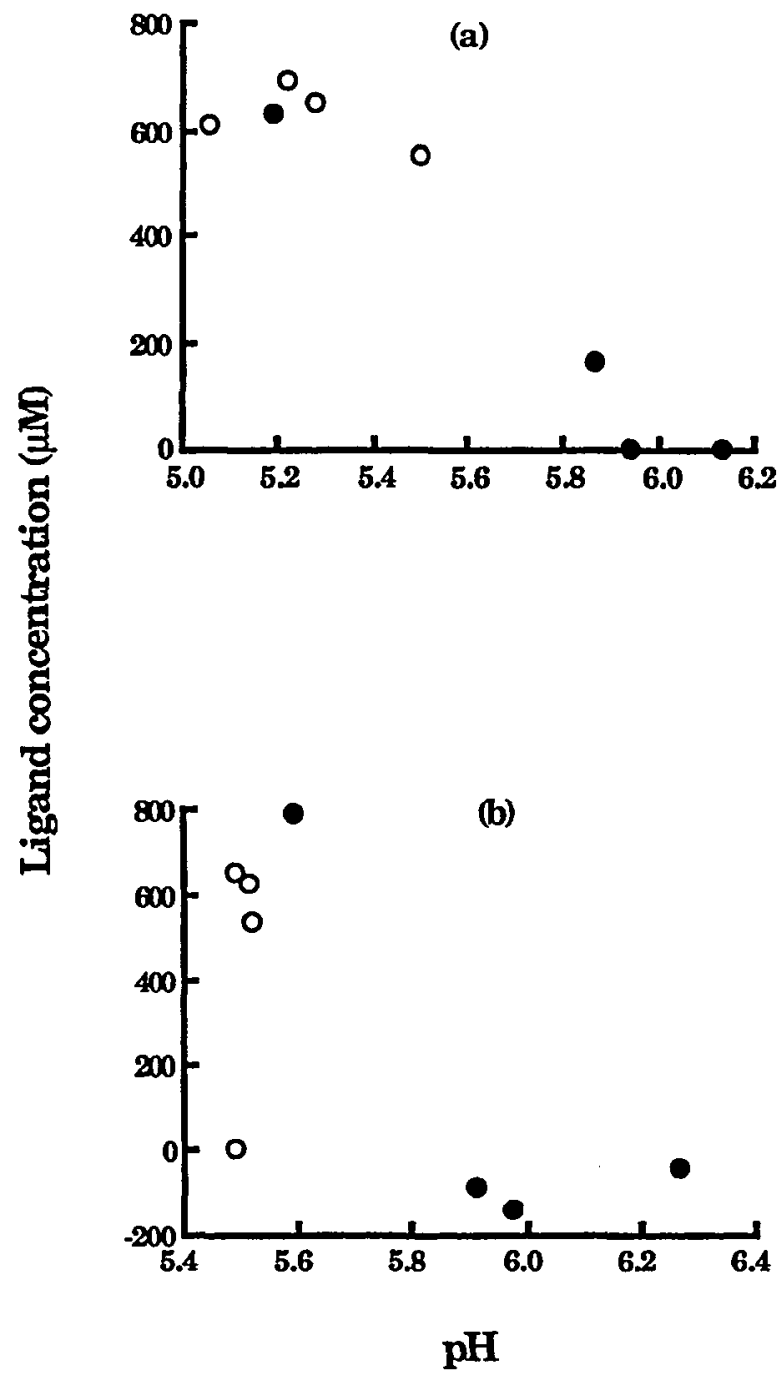

FIGURE 8. The relationship between $\mathrm{pH}$ and the concentration of (a) citrate and (b) catechol in sterile (O) and nonsterile soils (O). 

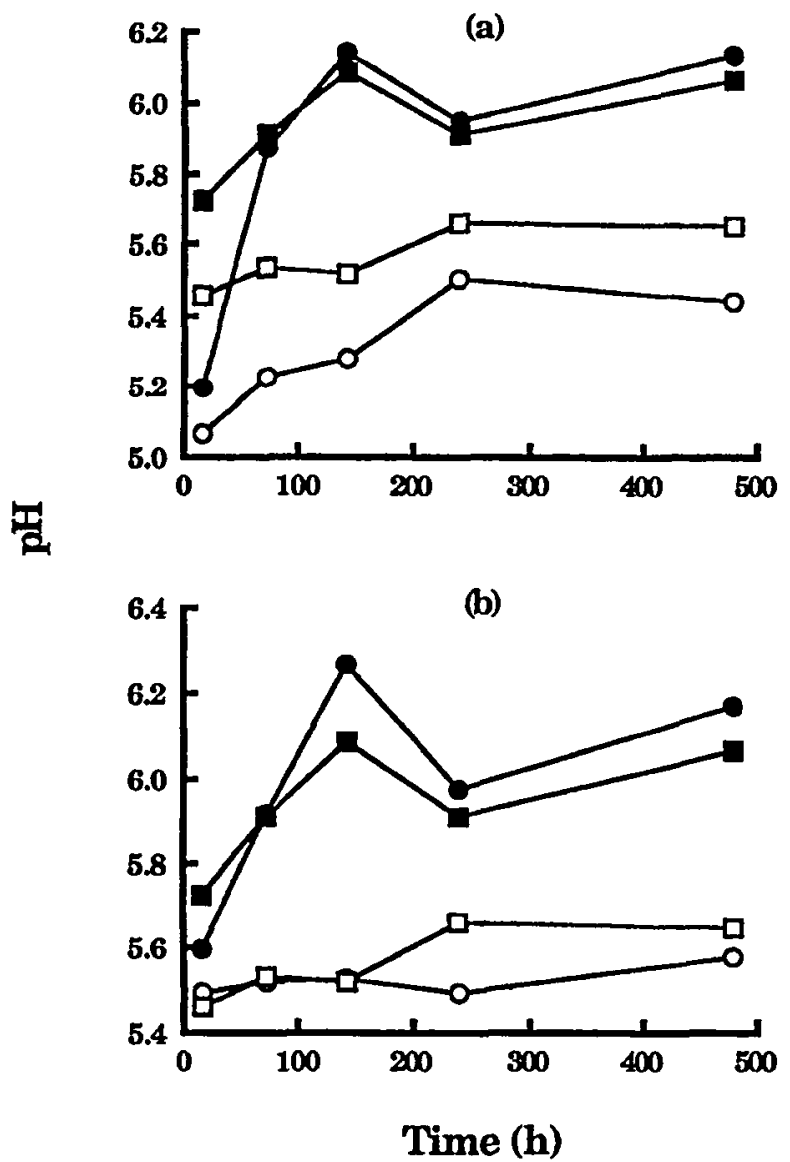

FIGURE 9. The relationship between reaction time and the solution $\mathrm{pH}$ in the absence (square symbols) or presence (round symbols) of (a) citrate and (b) catechol in sterile lopen symbols) and non-sterile soils (closed symbols). 


\section{DISCUSSION}

Changes in $\mathrm{Zn}$ adsorption with time in the presence of organic ligands were related to changes in $\mathrm{pH}$ and $\mathrm{Zn}$ complexation associated with the addition and breakdown of the organic ligands and the technique of sterilization.

Zinc adsorption was demonstrated to be greater in the non-sterile than in the sterile soil, particularly in the presence of citrate. The greater adsorption was due to the higher $\mathrm{pH}$ and the lower ligand concentrations in the non-sterile soils than in the sterile soils. The higher solution $\mathrm{pH}$ of the non-sterile soils was partly due to the activities of the soil micro-organisms that were present and partly due to the technique of sterilization.

Sterilization decreased $\mathrm{pH}$ at any one time interval and prevented microbial decomposition of the organic ligand. Both these factors decreased adsorption if a $\mathrm{Zn}$ ligand complex was formed.

As time of adsorption increased, $\mathrm{Zn}$ adsorption by unsterile soil increased due to the breakdown of organic ligands which had initially prevented $\mathrm{Zn}$ complexation, and due to an increase in $\mathrm{pH}$ due to the addition and breakdown of the ligands. In sterilized soil, $\mathrm{Zn}$ adsorption also increased with time due to changes in $\mathrm{pH}$ which were related to the addition of citrate but not to its decomposition. The latter mechanism had the least effect on adsorption. The increase in adsorption with time could also have been partly due to $\mathrm{Zn}$ ingestion by micro-organisms in non-sterile soils. This could explain the small increase $(<6 \%)$ in $\mathrm{Zn}$ absorption observed between 17 and $240 \mathrm{~h}$.

The effect of the reaction time on the $\mathrm{pH}$ of the soil solution may have been due directly or indirectly to the activities of the soil micro-organisms. The larger increase in $\mathrm{pH}$ of the non-sterile soil than that of the sterile soil in the absence of a ligand may indicate the direct effect of the microbial activity, whereas the larger increase in non-sterile soil than in the sterile soil in the presence of citrate may indicate the indirect effect of the microbial activity.

A comparison of the $\mathrm{pH}$ of non-sterile soil in the presence and absence of citrate indicated the breakdown of the ligand included the production of $\mathrm{OH}^{-}$or consumption of $\mathrm{H}^{+}$. The change in $\mathrm{pH}$ due to the addition of the ligand in sterile soil was only observed for citrate and presumably was a result of $\mathrm{pH}$ buffering by the soil neutralizing dissociated $\mathrm{H}^{+}$from the citric acid. Catechol would be completely associated at the initial $\mathrm{pH}$ of the soil, and hence, would not be expected to decrease $\mathrm{pH}$. 
The organic ligands decreased $\mathrm{Zn}$ adsorption in a similar manner as found in earlier work (2). In the presence of citrate, the charge on the complex species is an important factor in determining the adsorption of $\mathrm{Zn}$. The $\mathrm{pH}$ of solution in this study were all higher than p.z.s.e. of the soil [p.z.s.e. $=\mathrm{pH} \mathrm{3.9;} \mathrm{(2)].} \mathrm{The}$ adsorption of $\mathrm{Zn}$, therefore, decreased with increasing concentration of Zncit because the negatively charged $\mathrm{Zn}$ species was not adsorbed onto the negatively charged surfaces (16). In the presence of catechol, the adsorption of $\mathrm{Zn}$ was similar to that in its absence because catechol complexed only slightly with $\mathrm{Zn}$, and hence, there was no effect of catechol on $\mathrm{Zn}$ adsorption (2). However, most of the variation in $\mathrm{Zn}$ adsorption in this study could also be explained by the combined effect of the complexed $\mathrm{Zn}$ species plus $\mathrm{ZnOH}^{+}$.

The results of this work indicated that the effect of organic ligands is only transitory $(17-48 \mathrm{~h}$ ) if the organic ligands are broken down by microorganisms. In the rhizosphere, however, organic ligands such as citrate are being continually produced either by exudation from plants (16), or by microbial breakdown of more complex organic material $(17,18)$. Therefore in the dynamic environment of the rhizosphere, organic ligands may still have an important influence on $\mathrm{Zn}$ concentration in solution.

\section{ACKOWLEDGEMENT}

The work was funded by the Wheat Committee of Westem Australia.

\section{REFERENCES;}

1. Farrah, H. and W. F. Pickering. 1976. The sorption of zinc species by clay minerals. Aust. J. Chem. 29:1649-1656.

2. Chairidchai, P. and G. S. P. Ritchie. 1990. Zinc adsorption by a lateritic soil in the presence of organic ligands. Soil Sci. Soc. Am. J. 54:1242-1248.

3. Pareek, R. P. and A. C. Gaur. 1973. Organic acids in rhizosphere of Zea mays and Phaseolus aureus plants. Plant and Soil 39:441-444.

4. Barber, S. A. 1984. Soil Nutrient Bioavailability, a Mechanistic Approach. John Wiley and Sons, New York, 398 p.

5. Stevenson, F. J. and M. S. Ardakani. 1972. Organic matter reactions involving micronutrients in soils, pp. 79-114. IN: J. J. Mortvedt, et al. (eds.) Micronutrients in Agriculture. Soil Science Society of America, Madison, WI.

6. Lindsay, W. L. 1972. Zinc in soils and plant. Adv. Agron. 24:147-186. 
7. Rovira, A. D. 1969. Plant root exudates. Bot. Rev. 35:35-57.

8. Kraffczyk, I., G. Trolldenier, and H. Beringer. 1984. Soluble root exudates of maize: Influence of potassium supply and rhizosphere mictoorganisms. Soil Biol. Biochem. 16:315-322.

9. Pelczar, M. J., R. D. Reid, and E. C. S. Chan. 1977. Microbiology. TATA McGraw-Hill Publishing Co. Ltd., New Delhi, India.

10. Beg, M. M., Q. S. Usmani, and I. C. Shukla. 1977. Spectrophotometric determination of pyrocatechol, resorcinol and phloroglucinol with potassium iodate in dilute nitric acid. Analyst 102:306-307.

11. Lee, K. S. and D. W. Lee. 1968. Spectrophotometric determination of some organic acids with ferric 5-Nitrosalicylate complex. Anal. Chem. 40:20492052.

12. Cabaniss, S. E. 1987. Titrator: An interactive program for aquatic equilibrium calculations. Environ. Sci. Technol. 21:209-210.

13. Lindsay, W. L. 1979. Chemical Equilibria in Soils. John Wiley and Sons, New York, NY.

14. Martell, A. E. and R. M. Smith. 1977. Critical Stability Constants: Other Organic Ligands, Volume 3. Plenum Press, New York, NY.

15. Chairidchai, P. and G. S. P. Ritchie. 1992. The effect of $\mathrm{pH}$ on zinc adsorption by a lateritic soil in the presence of citrate and oxalate. J. Soil Sci. (in press).

16. Inoue, K. and P. M. Huang. 1984. Influence of citric acid on the natural formation of imogolite. Nature 308:58-60.

17. Lewis, J. A. and R. L. Starkey. 1969. Decomposition of plant tannins by some soil micro-organisms. Soil Sci. 107:235-241.

18. Flaig, W. 1971. Organic compounds in soil. Soil Sci. 111:19-33. 